\title{
Seroprevalence and risk factors associated with visceral leishmaniasis in dogs in Jaciara, State of Mato Grosso
}

\author{
Priscila Marcidelli Lopes ${ }^{[1]}$, Eveline da Cruz Boa Sorte ${ }^{[1]}$, Naiani Domingos Gasparetto ${ }^{[1]}$, \\ Cenita Maria Oliveira ${ }^{[2]}$, Arleana do Bom Parto Ferreira de Almeida ${ }^{[3]}$ \\ and Valéria Régia Franco Sousa ${ }^{[3]}$
}

[1]. Programa de Pós-Graduação em Ciências Veterinárias, Universidade Federal de Mato Grosso, Cuiabá, MT. [2]. Vigilância Ambiental, Secretaria Municipal de Saúde de Jaciara, Jaciara, MT. [3]. Departamento de Clínica Médica Veterinária, Universidade Federal de Mato Grosso, Cuiabá, MT.

\begin{abstract}
Introduction: Visceral leishmaniasis is a neglected disease. Jaciara, State of Mato Grosso has the most cases. This study aimed to determine the risk factors and seroprevalence of canine visceral leishmaniasis in urban and rural areas. Methods: This cross-sectional study of domestic dogs used enzyme-linked immunosorbent assay and indirect immunofluorescence test. Results: The prevalence was $54.7 \%$ among 345 analyzed samples. Short coat, age of 1-6 years, and living less than $100 \mathrm{~m}$ from vegetation posed the highest infection risks. Conclusions: Certain dog behaviors and characteristics, and their correlation with environmental conditions, were relevant in the high prevalence of canine leishmaniasis in Jaciara.
\end{abstract}

Keywords: Cerrado. Epidemiology. Leishmania chagasi.

Visceral leishmaniasis (VL) is a neglected disease. Approximately 3,500 cases are reported annually, and approximately $10 \%$ of these lead to death ${ }^{1}$. In Mato Grosso, canine visceral leishmaniasis (CVL) has been identified in 41 municipalities with an average seroprevalence of $9 \%$ (1998-2005). The municipality of Jaciara has the highest recorded rate of seropositive dogs $(40 \%)$ and one of the highest rates of human infection $(5.8 \%)^{2}$. Lutzomyia longipalpis and Lutzomyia cruzi are vectors incriminated in the transmission of Leishmania chagasi (syn. Leishmania infantum) ${ }^{3}$.

From an epidemiological point of view, dogs are important in the urban environment because of the higher prevalence of the disease in this setting, and a large number of asymptomatic dogs harbor the parasite in their skin and thereby provide a source of infection for the vector ${ }^{1}$. Epidemiological studies indicate that the infection is associated with particular risk factors such as the length of an animal's coat, the areas in the house frequented by the $\operatorname{dog}^{4}$, and the socioeconomic and demographic indicators of the region ${ }^{5}$. The aim of this study was to determine the seroprevalence of CVL in urban and rural areas by identifying the risk factors involved in the transmission of this disease in the municipality of Jaciara, State of Mato Grosso.

\footnotetext{
Address to: Dra. Valéria Régia Franco Sousa. Depto. de Clínica Médica Veterinária/UFMS. Av. Fernando Correa da Costa 2367, Bairro Boa Esperança, 78060-900 Cuiabá, MT, Brasil.

Phone: 5565 3615-8662

e-mail: regia@ufmt.br

Received 5 February 2014

Accepted 22 May 2014
}

A cross-sectional study was conducted from June 2010 to May 2011 in the municipality of Jaciara $\left(16^{\circ} 02^{\prime} 30^{\prime \prime} \mathrm{S} ; 54^{\circ} 59^{\prime}\right.$ $45^{\prime \prime} \mathrm{W}$ ), which is situated in the southern region of the State of Mato Grosso. The town is located in the Cerrado biome; its climate is predominantly semi-humid tropical; and its population is 25,666 inhabitants ${ }^{6}$.

Samples were collected in areas with a history of human cases and, on request, in the following neighborhoods in urban areas: Center, Jardim Aeroporto, Jardim Aurora, Jardim Esmeralda, Jardim Clementina, Jardim Leblon, Jardim Vitória, João de Barro, Nova Jaciara, Santa Luzia, São Lourenço, Santo Antônio, São Sebastião, Santa Rita and Vila Planalto (Figure 1); samples were also collected in the following rural areas: Brilhante, São Francisco, 25 de Novembro, Celma District, and seven farms on the BR 364 highway.

The sampling was estimated using a confidence interval (CI) of $95 \%$ and an acceptable error of $5 \%$, assuming a corrected finite population of 4,015 (Municipal Health Department: Personal Communication, 2010) and a prevalence of $40 \%{ }^{2}$. The owners signed voluntary, informed consent forms to allow clinical examination of their animals and collection of samples from the animals, and to provide information on characteristics such as the origin of the dog, its breed (i.e., defined breed or mongrel), sex, castration status (i.e., yes or no), age $(<1$ year, $\geq 1-6$ years or $>6$ years), length of coat, time living in the house, access to the streets and rural area (i.e., urban dogs), household status (i.e., indoor or outdoor dog), presence of other dogs and animals, vaccination against the disease, use of repellent collar on the dog, and environmental characteristics. In addition, the population's knowledge of the disease was investigated. 


\section{Human visceral leishmaniasis}

\section{Lutzomyia cruzi}

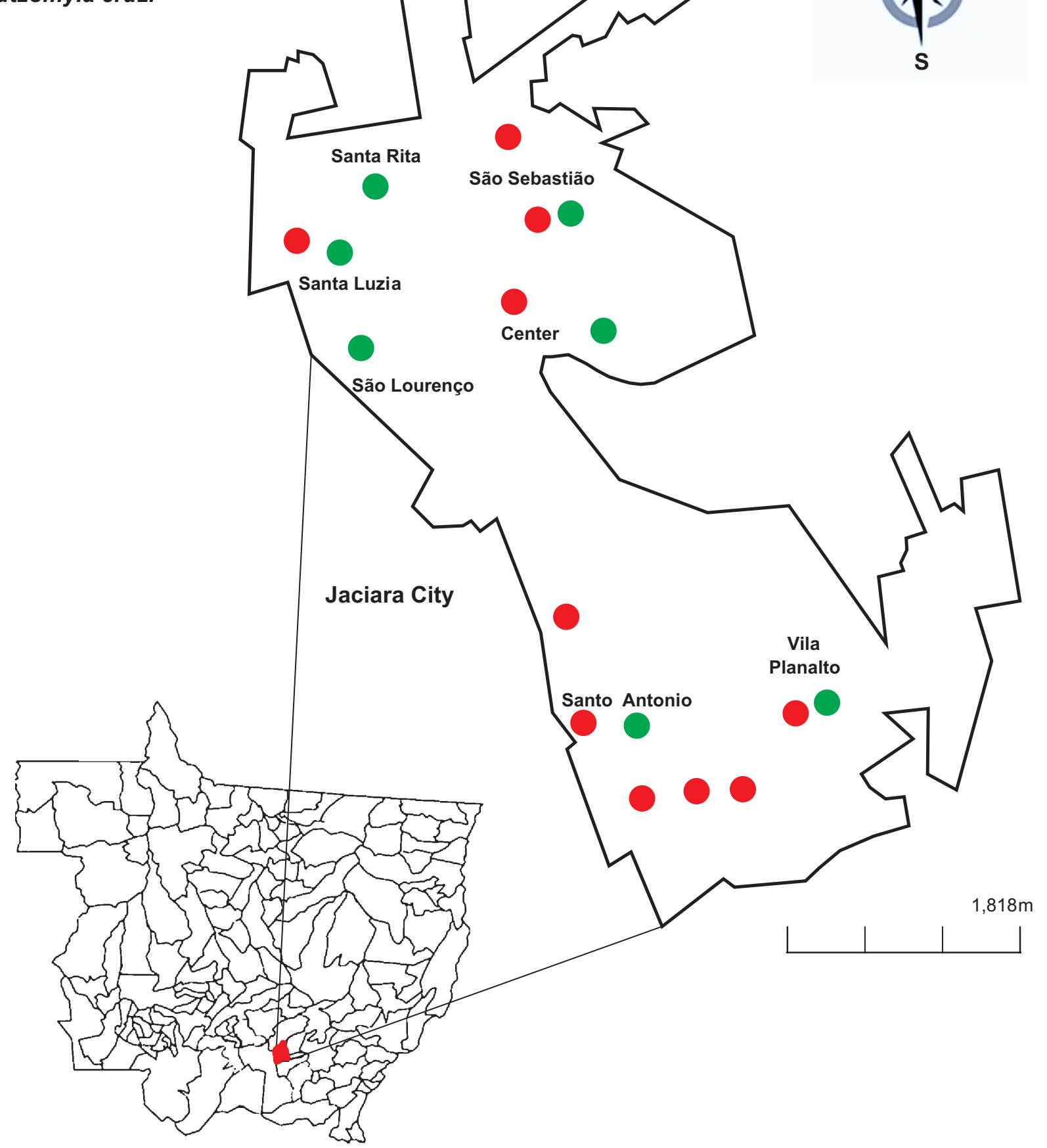

\section{State of Mato Grosso}

FIGURE 1 - Neighborhoods analyzed for canine visceral leishmaniasis in the municipality of Jaciara, State of Mato Grosso, based on the distribution of cases and the presence of visceral leishmaniasis and Lutzomyia cruzi. 
The dogs were examined and classified as symptomatic or asymptomatic ${ }^{7}$. Blood was collected by jugular venipuncture. After centrifugation, the serum samples were put into microtubes and stored at $-20^{\circ} \mathrm{C}$ until the serological tests could be performed. These consisted of the immunoenzymatic assay (ELISA) and the indirect immunofluorescence test (IFAT), which were performed using commercial kits (Bio Manguinhos/FIOCRUZ, Rio de Janeiro, Brazil) in accordance with the manufacturer's recommendations. The IFAT is considered the gold standard ${ }^{1}$.

Statistical analyses were performed using the Epi Info software (Center for Disease Control and Prevention [CDC], Atlanta, GA, USA), the chi-square or Fisher's exact test, and logistic regression model. The level of significance was 0.05 . The agreement between the techniques was investigated using the kappa index.

This study was conducted in accordance with the ethical principles approved by the Ethics Committee for Animal Research of Federal University of Mato Grosso [Comitê de Ética no Uso de Animais-Universidade Federal De Mato Grosso (CEUA-UFMT)] under protocol number 23108.024440/10-0.

Of the 345 samples collected, 296 samples were from urban areas and 49 samples were from rural areas. Of this total, 174 $(58.7 \%)$ urban samples and $15(30.6 \%)$ rural samples were reactive, based on IFAT, with an overall prevalence of $54.7 \%$. The overall prevalence detected by ELISA was $44.9 \%$. The agreement between IFAT and ELISA was weak $(\kappa=0.52)$. The dilutions of the predominant antibodies detected by IFAT were $640(38 \%)$, 320 (11.1\%), 160 (10.1\%), 40 (30.7\%), and 80 (10.1\%).

When analyzing the chance that the dogs in each region would acquire the infection, the risk was three times higher in urban areas than in rural areas $(\mathrm{OR}=3.23 ; 1.62<\mathrm{OR}<6.53)$.
Of the seropositive dogs, $119(63 \%)$ dogs were asymptomatic for CVL and $70(20.3 \%)$ dogs were symptomatic, with a statistically significant difference between the two groups [p < 0.001; OR 2.94 (1.71-5.09)]. The main clinical signs were weight loss, onychogryphosis, ophthalmic disorders, lymphadenopathy, apathy, and dermopathies.

Table 1 presents the risk factors observed in this study. There were no statistically significant differences between any of the areas studied with regard to sex, breed, being born in the home, having free access to the streets or to a rural environment (in the case of urban dogs), the presence of other dogs, the death of other animals with CVL that lived at the location, or the presence of a sick animal or person in the neighborhood ( $p>0.05)$.

Control measures such as the use of repellent collars and/ or environmental insecticides and vaccines against CVL, and animal population control through castration were also investigated. Only a small number of owners used these measures on their animals $(6.3 \%$, repellent collars; $0.2 \%$, vaccines against $\mathrm{CVL}$; and $1.1 \%$, castration).

The prevalence of CVL in Brazil varies greatly by region ${ }^{8}$. The reported prevalence within the State of Mato Grosso is 3.4\% in Cuiabá ${ }^{5}$ and $40 \%$ in Jaciara ${ }^{2}$. In our study area, the prevalence was $54.7 \%$, thus exceeding the $40 \%$ found previously ${ }^{2}$ using the same methodology. Different frequencies of infection in humans and dogs are to be expected because of the use of different diagnostic methods and the temporal variability and differences in the dynamics of transmission between the canine and human populations ${ }^{9}$, and because of differences resulting from the means used to obtain samples since some samples were obtained by request.

TABLE 1 - Risk factors for infection by Leishmania chagasi in dogs in urban and rural areas in the municipality of Jaciara, State of Mato Grosso.

\begin{tabular}{|c|c|c|}
\hline Variable & \multicolumn{2}{|c|}{ Multivariate analysis } \\
\hline Dogs born in Jaciara ${ }^{\mathrm{a}, \mathrm{c}, \mathrm{c}}$ & $\leq 0.01$ & $16.21(8.87-29.60)$ \\
\hline Residence time $>1$ years & 0.01 & $1.98(1.12-3.47)$ \\
\hline Absence of henhouse/pigsty ${ }^{b, c}$ & 0.00 & $0.24(0.12-0.47)$ \\
\hline Trees in the yard (fruit tree) ) $^{\mathrm{a}, \mathrm{b}, \mathrm{c}}$ & 0.02 & $1.87(1.07-3.26)$ \\
\hline \multirow[t]{2}{*}{ Vegetation (forest, river, wasteland) ${ }^{\mathrm{a}}$} & 0.03 & $2.60(1.34-5.02)$ \\
\hline & \multicolumn{2}{|c|}{ Univariate analysis } \\
\hline Variable & $\mathrm{p}$ & odds ratio \\
\hline Distance $<100 \mathrm{~m}$ (from forest, river, wasteland) (f,c $^{\mathrm{a}}$ & 0.01 & $2.28(1.07-2.05)$ \\
\hline
\end{tabular}

${ }^{\mathrm{a}}$ urban area; ${ }^{\mathrm{b}}$ rural area; ${ }^{\mathrm{c}}$ total. 
With regard to the epidemiology of VL, occurrences were commonly reported in rural areas in the past. However, an increasing urbanization of the disease has been observed ${ }^{8,10}$. This was also observed in the present study: the risk of infection was three times higher among dogs living in urban areas.

Urbanization is associated with ecotypes that are favorable to the development and adaptation of the vector. This characteristic was also present in Jaciara because many of its dwellings are close to natural environments. Associations with other risk factors for infection were also found such as the presence of plantations (e.g., fruit trees), the proximity of homes with dogs to forests, wastelands, lush vegetation, and areas that had recently undergone environmental change, all of which are conditions suitable to the development of the vector ${ }^{11}$.

The Brazilian Ministry of Heath has recommended using two serological techniques - ELISA as the screening test and IFAT as the confirmatory method - because this approach has higher sensitivity and reduces the number of false positives ${ }^{12}$. This had previously been recommended by the Ministry of Health, but the techniques now used are ELISA and Dual Path Platform technology (DPP ${ }^{\circledR}$ CVL rapid test/Bio Manguinhos/ FIOCRUZ, Rio de Janeiro, Brazil). The latter employs the immunochromatographic principle, which is fast and easy to use $^{13}$. The agreement between the two techniques was weak, but the prevalence of high titers of antibodies in IFAT showed that infection was present in these animals, thus decreasing the chances of cross-reactions ${ }^{7}$. This justifies the use of this technique for analyzing risk factors. Isolation in a culture medium for the identification of the species has been recommended; however, the technique was not used in this study.

The technique that was used was more sensitive for detecting the symptomatic dogs among the reactive dogs $(\mathrm{p}<0.05)$. Specific antibodies can often be detected before the disease appears and their concentrations may be positively associated with the presence and severity of clinical signs, although some of the dogs may remain asymptomatic for more than five years ${ }^{14}$. Among the symptomatic dogs, the most frequent signs have commonly been cited by other authors ${ }^{5}$.

In the evaluated samples, there were no statistically significant differences regarding sex or breed $(p>0.05)$; this was also observed in Cuiabás. However, an age greater than 1 year was associated with a higher infection rate. This is corroborated by other epidemiological studies that have shown that the peak incidence of CVL seropositivity occurs at the age of 2-5 years, which is possibly associated with a greater time of exposure to the vector ${ }^{14}$.

The dogs in the municipality of Jaciara (i.e., an urban area) presented a higher risk of being seropositive because this region is endemic for the disease ${ }^{3}$. This also confirms the autochthonous nature of CVL in this municipality, as does the fact that the dogs had been living in this locality for more than 1 year. Situations in which household animals remain outdoors in areas surrounding the house have been considered a risk factor by other authors ${ }^{8,14}$. This was also observed in the present study.

Short-coated dogs have twice the risk of infection as longhaired dogs because the protection afforded by long hair hinders biting by phlebotomines ${ }^{4}$; In fact, all dogs in the rural areas were had short coats.

The absence of henhouses or pigsties was a protective factor against infection and may have been associated with a feeding preference among the vectors for poultry or other animals that can act as a source of blood for female sandflies ${ }^{15}$, and thereby favor continuation of the vector in this environment.

Issues relating to health education are important in the fight against this disease. Although, the knowledge of the owners about the sandflies be related to increased risk of infection, a result of exposure to the vector, as reported in the State of Minas Gerais ${ }^{8}$ or of the ineffectiveness of control measures in the study area considered endemic. Furthermore, few owners implemented control measures such as using repellent collars and/or environmental insecticides ${ }^{4}$, or having their dogs vaccinated against CVL or castrated as a means of population control. These measures were also investigated in this population.

In conclusion, Jaciara had a high prevalence of risk factors favorable to CVL. These were particularly associated with the environmental conditions, which are important in maintaining the epidemiological cycle of the disease.

\section{ACKNOWLEDGMENTS}

The authors would like to thank the Secretaria de Estado de Saúde de Mato Grosso, Secretaria Municipal de Saúde de Jaciara, State of Mato Grosso, and FIOCRUZ (Bio Manguinhos).

\section{CONFLICT OF INTEREST}

The authors declare that there is no conflict of interest.

\section{FINANCIAL SUPPORT}

Coordenação de Aperfeiçoamento de Pessoal de Nivel Superior (CAPES).

\section{REFERENCES}

1. Ministério da Saúde. Secretaria de Vigilância em Saúde. Departamento de Vigilância Epidemiológica. Manual de Controle da Leishmaniose Visceral. Série A. Normas e Manuais Técnicos. Brasília: Ministério da Saúde; 2006.

2. Mestre GLC, Fontes CJF. A expansão da epidemia de leishmaniose visceral no Estado de Mato Grosso, 1998-2005. Rev Soc Bras Med Trop 2007; 40:42-48.

3. Missawa NA, Veloso MAE, Maciel GBML, Michalsky EM, Dias ES. Evidência de transmissão de leishmaniose visceral por Lutzomyia cruzi no município de Jaciara, Estado de Mato Grosso, Brasil. Rev Soc Bras Med Trop 2011; 44:76-78.

4. Coura-Vital W, Reis AB, Fausto MA, Leal GG, Marques MJ, Veloso VM, et al. Risk factors for seroconversion by Leishmania infantum in a cohort of dogs from an endemic area of Brazil. PLoS One 2013; 22:e71833. 
5. Almeida ABPF, Faria RP, Pimentel MFA, Dahroug MAA, Turbino NCMR, Sousa VRF. Inquérito soroepidemiológico de leishmaniose canina em áreas endêmicas de Cuiabá, Estado de Mato Grosso. Rev Soc Bras Med Trop 2009; 42:156-159.

6. Instituto Brasileiro de Geografia e Estatística (IBGE). Cidades 2010. [Cited 2011 January 9]. Available at: http://www.ibge.gov.br/ cidadesat/topwindow.htm?1/.

7. Solano-Gallego L, Koutinas A, Miró G, Cardoso L, Pennisi MG, Ferrer L, et al. Directions for the diagnosis, clinical staging, treatment and prevention of canine leishmaniosis. Vet Parasitol 2009; 165:1-18.

8. Coura-Vital W, Marques MJ, Veloso VM, Roatt BM, Aguiar-Soares RDO, Reis LES, et al. Prevalence and factors associated with Leishmania infantum infection of dogs from an urban area of Brazil as identified by molecular methods. PLoS Negl Trop Dis 2011; 5:e1291.

9. Felipe IMA, Aquino DMC, Kuppinger O, Santos MDC, Rangel MES, Barbosa DS, et al. Leishmania infection in humans, dogs and sandflies in a visceral leishmaniasis endemic area in Maranhão, Brazil. Mem Inst Oswaldo Cruz 2011; 106:207-211.

10. Dantas-Torres F. Canine leishmaniasis in South America. Parasit Vectors $2009 ; 2: 1-8$.
11. Brazuna JC, Silva EA, Brazuna JM, Domingos IH, Chaves N, Honer MR, et al. Profile and geographic distribution of reported cases of visceral leishmaniasis in Campo Grande, State of Mato Grosso do Sul, Brazil, from 2002 to 2009. Rev Soc Bras Med Trop 2012; 45:601-606.

12. Lira RA, Cavalcanti MP, Nakazawa M, Ferreira AG, Silva ED, Abath FG, et al. Canine visceral leishmaniosis: A comparative analysis of the EIE-leishmaniose-visceral-canina-Bio-Manguinhos and the IFI-leishmaniose-visceral-canina-Bio-Manguinhos kits. Vet Parasitol 2006; 37:11-16.

13. Grimaldi Jr G, Teva A, Ferreira AL, Santos CB, Pinto I, de-Azevedo CT, et al. Evaluation of a novel chromatographic immunoassay based on Dual-Path Platform technology (DPP ${ }^{\circledR}$ CVL rapid test) for the serodiagnosis of canine visceral leishmaniasis. Trans R Soc Trop Med Hyg 2012; 106:54-59.

14. Saridomichelakis MN. Advances in the pathogenesis of canine leishmaniosis: epidemiologic and diagnostic implications. Vet Dermatol 2009; 20:471-489.

15. Missawa NA, Lorosa, ES, Dias ES. Preferência Alimentar de Lutzomyia longipalpis (Lutz \& Neiva, 1912) em área de transmissão de leishmaniose visceral em Mato Grosso. Rev Soc Bras Med Trop 2008; 41:365-368. 